\title{
Novel picornavirus (family Picornaviridae) from freshwater fishes (Perca fluviatilis, Sander lucioperca, and Ameiurus melas) in Hungary
}

\author{
Renáta Hargitai ${ }^{1}$ Péter Pankovics ${ }^{1}$ Ákos Boros ${ }^{1} \cdot$ Róbert Mátics $^{2}$ - Eda Altan ${ }^{3}$ - Eric Delwart ${ }^{3,4}$ - Gábor Reuter ${ }^{1}$ (1)
}

Received: 1 March 2021 / Accepted: 21 May 2021 / Published online: 13 July 2021

(c) The Author(s) 2021

\begin{abstract}
In this study, a novel picornavirus (perchPV/M9/2015/HUN, GenBank accession no. MW590713) was detected in eight (12.9\%) out of 62 faecal samples collected from three (Perca fluviatilis, Sander lucioperca, and Ameiurus melas) out of 13 freshwater fish species tested and genetically characterized using viral metagenomics and RT-PCR methods. The complete genome of perchPV/M9/2015/HUN is 7,741 nt long, excluding the poly(A) tail, and has the genome organization 5'UTR IRES-?/P1(VP0-VP3-VP1)/P2 (2 $\left.\mathrm{A}_{1}{ }^{\mathrm{NPG} \downarrow \mathrm{P}}-2 \mathrm{~A}_{2}{ }^{\mathrm{H}-\mathrm{box} / \mathrm{NC}}-2 \mathrm{~B}-2 \mathrm{C}\right) / \mathrm{P} 3\left(3 \mathrm{~A}-3 \mathrm{~B}^{\mathrm{VPg}}-3 \mathrm{C}^{\mathrm{Pro}}-3 \mathrm{D}^{\mathrm{Pol}}\right) / 3$ 'UTR-poly(A). The P1, 2C, and 3CD proteins had $41.4 \%, 38.1 \%$, and $47.3 \%$ amino acid sequence identity to the corresponding proteins of Wenling lepidotrigla picornavirus (MG600079), eel picornavirus (NC_022332), and Wenling pleuronectiformes picornavirus (MG600098), respectively, as the closest relatives in the genus Potamipivirus. PerchPV/M9/2015/HUN represents a potential novel fishorigin species in an unassigned genus in the family Picornaviridae.
\end{abstract}

\section{Introduction}

Picornaviruses are small non-enveloped viruses with a positive-sense, single-stranded RNA genome, belonging to the family Picornaviridae. The family consists of 158 species grouped into 68 genera (https://www.picornaviridae.com/ index.html). Not only is the known genetic diversity of the picornaviruses expanding rapidly but the number of known host species is also increasing. Picornaviruses have been identified in a wide range of vertebrates from fish to mammals, including humans. Most of the known picornaviruses were found in mammals and birds, but in recent years, novel

Handling Editor: Kalpana Agnihotri.

Nucleotide sequence data reported are available in the DDBJ/ EMBL/GenBank databases under the accession number MW590713.

Gábor Reuter

reuter.gabor@gmail.com

1 Department of Medical Microbiology and Immunology, Medical School, University of Pécs, Szigeti út 12., 7624 Pecs, Hungary

2 Hungarian Nature Research Society, Ajka, Hungary

3 Vitalant Research Institute, San Francisco, CA, USA

4 University of California, San Francisco, CA, USA picornaviruses have also been identified in lower vertebrates, including amphibians (newts) [16, 19], reptiles (tortoises) $[8,15]$, and fish. In the last group, six official fish-origin picornavirus genera - Limnipivirus from bluegill [4], carp [13], and minnow [18]; Potamipivirus from eel [9] and stickleback [12]; Fipivirus from sharpbelly, crossorhombus, jack mackerel, wrasse, and banjofish [20]; Symapivirus from triplecross lizardfish [20]; Rajidapivirus from sharpspine skate [20], and Danipivirus from zebrafish [1] - have been established and approved (https://talk.ictvonline.org/ictv-reports/ ictv_online_report/positive-sense-rna-viruses/w/picornavir idae.https://www.picornaviridae.com/index.html), although there are further unassigned picornaviruses that have been discovered in different fish species [20].

Some picornaviruses are important viral pathogens, causing a wide range of diseases in humans and wild, domestic, and laboratory animals. However, little is known about the diversity, epidemiology, and disease-causing potential of fish picornaviruses [14].

In this study, we report the identification and complete genome characterization of a potentially novel picornavirus in freshwater fishes (Perca fluviatilis, Sander lucioperca, and Ameiurus melas) in Hungary. 


\section{Materials and methods}

A total of 62 faecal samples were collected directly from 13 different freshwater fish (Supplementary Table S1) living in natural and artificial open-air fishponds in the vicinity of Szarvas (Eastern Hungary) in the year 2015. The fish showed no clinical signs of disease during sample collection and were released immediately after sampling.

A specimen pool containing faecal samples from three European perch (M9, M13 and M15) were selected for viral metagenomics analysis. Briefly, $200 \mu \mathrm{l}$ of PBSdiluted specimen was passed through a $0.45-\mu \mathrm{m}$ sterile filter (Millipore) and centrifuged at $6,000 \times g$ for $5 \mathrm{~min}$. The filtrate was then treated with a mixture of DNases and RNases (Turbo DNase, Invitrogen; Baseline Zero DNase, Epicentre Biotechnologies; Benzonase Nuclease, Novagen; RNase A, Fermentas) at $37^{\circ} \mathrm{C}$ for 2 hours to digest unprotected nucleic acids [17]. Viral-particle-protected nucleic acids were extracted using a MagMAX Viral RNA Isolation Kit (Ambion, Austin, USA) with RNase inhibitor (RiboLock RNase Inhibitor, Fermentas) during the elution step. Sequence-independent random RT-PCR amplification [21] with 20 PCR cycles was used, and a viral cDNA library with 250 base-paired ends was constructed using a Nextera XT DNA Library Preparation Kit (Illumina). The library was sequenced on an Illumina MiSeq platform according to the manufacturer's instructions. The metagenomic reads were trimmed, assembled de novo [7], and analyzed using an in-house pipeline [17]. Briefly, the singlets and assembled contigs greater than $250 \mathrm{bp}$ were compared to the GenBank [6] protein database using BLASTx (version 2.2.7) [2], using an E-value cutoff of 0.01. Candidate viral hits were then compared to a non-viral non-redundant protein database to remove false positive viral hits. Virus-family-level categorization of all viral metagenomic sequences was based on the best BLASTx scores (E-value $\leq 10^{-10}$ ). Metagenomic raw sequence read data are available upon request.

A sequence-specific screening primer pair (PerchPVscreen1-F/R, Supplementary Table S2) was designed for the $3 \mathrm{D}$ region to identify the viral genome of the study strain from the specimen pool. The PCR thermocycler program consisted of $3 \mathrm{~min}$ at $95^{\circ} \mathrm{C}, 40$ cycles for 30 $\mathrm{s}$ at $95^{\circ} \mathrm{C}, 20 \mathrm{~s}$ at $55^{\circ} \mathrm{C}$, and $30 \mathrm{~s}$ at $72^{\circ} \mathrm{C}$, and a final 3 -min extension at $72^{\circ} \mathrm{C}$ using a $\mathrm{C} 1000$ Touch Thermal Cycler (Bio-Rad). In addition, different sets of specific primers (Supplementary Table S2) were designed based on the sequences of the metagenomics reads/contigs and the amplified PCR products for the verification of the metagenomics contig and to obtain the complete viral genome sequence, including the 5 ' and 3 ' ends, of the study strain (perchPV/M9/2015/HUN). All faecal samples were tested individually by the RT-PCR method, using the PerchPV-screen2-F/R (Supplementary Table S2) screening primer pair.

Sequence alignments of the $\mathrm{P} 1,2 \mathrm{C}$, and $3 \mathrm{CD}$ regions were done using GeneDoc (version 2.7) and the MUSCLE web server based on the amino acid sequences of the studied fish picornavirus and representative picornaviruses available in the GenBank database. Phylogenetic analysis was performed using MEGA X (version 10.2.3), creating maximumlikelihood trees using the substitution model $\mathrm{LG}+\mathrm{F}+\mathrm{G}+\mathrm{I}$ for $\mathrm{P} 1$ and $3 \mathrm{CD}$ analysis and $\mathrm{LG}+\mathrm{G}+\mathrm{I}$ for $2 \mathrm{C}$, with 1000 bootstrap replicates as described previously [1]. Potential secondary RNA structures of the 5' and 3' UTRs of the analyzed picornavirus sequences were predicted using Mfold software [22].

The nucleotide (nt) and amino acid (aa) sequences of European perch picornavirus (perchPV/M9/2015/HUN) have been deposited in the GenBank database under the accession number MW590713.

\section{Results}

A specimen pool containing three faecal samples from European perch was subjected to viral metagenomics analysis. After de novo assembly of the 16,612,456 sequence reads, 58,855 reads from this pool were found to show similarity (BLASTx cutoff E-value $\leq 10^{-10}$ ) to viral sequences. The sequences with more than 100 reads were from unclassified viruses $(\mathrm{n}=13,542)$, as well as the families Parvoviridae $(\mathrm{n}=15,209)$, Dicistroviridae $(\mathrm{n}=12,081)$, Reoviridae $(\mathrm{n}$ $=5,360)$, Picornaviridae $(\mathrm{n}=3,198)$, Microviridae $(\mathrm{n}=$ 2,689), Circoviridae $(\mathrm{n}=1,825)$, Tombusviridae $(\mathrm{n}=794)$, Permutotetraviridae $(\mathrm{n}=643)$, Phycodnaviridae $(\mathrm{n}=289)$, Virgaviridae $(\mathrm{n}=170)$, and Nanoviridae $(\mathrm{n}=133)$.

Sequence reads/contigs corresponding to family Picornaviridae were selected for further analysis. The longest picornavirus contig was 3,423 nucleotides (nt) long, and the encoded protein had only $40.2 \%$ aa sequence identity to the $2 \mathrm{C} / 3 \mathrm{C}-3 \mathrm{D}$ region of eel picornavirus 1 strain $\mathrm{F} 15 / 5$ (NC_022332), a member of the species Potamipivirus $A$ in the genus Potamipivirus [9]. A sequence-specific screening primer pair was designed based on the $3 \mathrm{D}$ region of the picornavirus sequence contig (Supplementary Table S2) to identify the picornavirus strain in the specimen pool. One of the three specimens from European perch was RT-PCR positive, and this sample (M9) was selected for further study.

The complete genome - including the complete coding regions - of European perch picornavirus (perchPV/ M9/2015/HUN, MW590713) is 7,741 nt long excluding the poly(A) tail (Fig. 1). The genome organization is as follows:

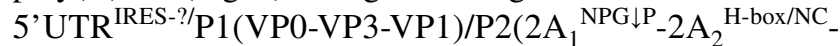
$2 \mathrm{~B}-2 \mathrm{C}) / \mathrm{P} 3\left(3 \mathrm{~A}-3 \mathrm{~B}^{\mathrm{VPg}}-3 \mathrm{C}^{\mathrm{Pro}}-3 \mathrm{D}^{\mathrm{Pol}}\right) / 3$ ' UTR-poly(A). It has 


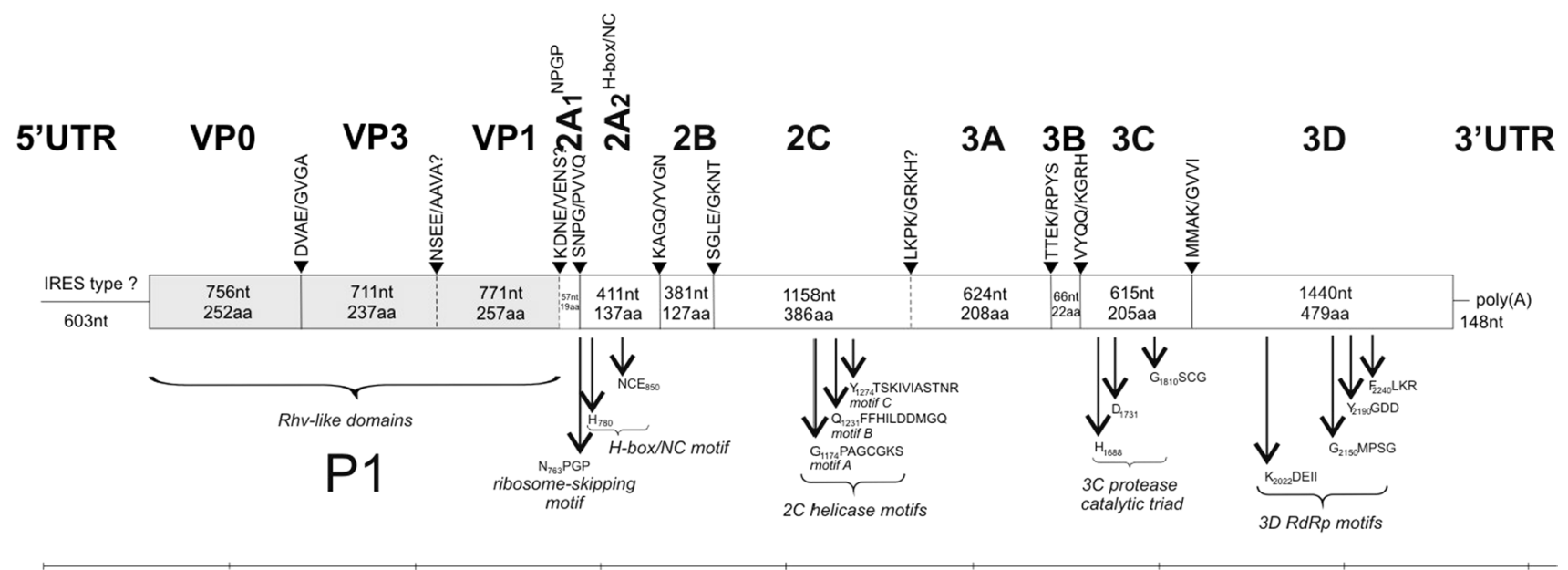

0

Fig. 1 Schematic genome organization of perch picornavirus strain perchPV/M9/2015/HUN (GenBank accession no. MW590713). The genome map is drawn to scale. VP0, VP3, and VP1 represent viral structural proteins and are shown in grey. Nucleotide (upper number) and amino acid (lower number) lengths are indicated in each gene box. Conserved picornaviral amino acid motifs and predicted

44.4\% $\mathrm{G}+\mathrm{C}$ content and a nucleotide composition of $31.6 \%$ A, $24 \% \mathrm{U}, 23.4 \% \mathrm{G}$, and $21 \% \mathrm{C}$. No nucleotide tandem repeats were found in the genome sequence.

The European perch picornavirus 5'UTR is $603 \mathrm{nt}$ long. The first in-frame AUG initiation codon is at nt position 604-606 in an optimal Kozak context (CACAA ${ }_{604}$ UGG, start codon in bold). Using a GenBank BLASTn search, a unique, 90-nt-long region with partial genetic similarity was found in the 5'UTR region of potamipivirus B1 (species Potamipivirus $B$, MK189163) from stickleback [12]. This nucleotide region (between nt position 374 and 463 of the 5'UTR of European perch picornavirus) has $81 \%$ nt sequence identity to the corresponding non-coding region of potamipivirus B1 (Fig. 2). The secondary RNA structure of the 5'UTR including the IRES is unknown in potamipiviruses. Based on the 5'UTR sequences of European perch picornavirus and the above 5'UTR sequences of potamipivirus B1, the construction of a predicted RNA secondary structure model was partially successful (Fig. 2). The sequence alignment showed that the majority of the nucleotide mutations maintained their base pairing (and therefore the predicted secondary RNA structure) in the aligned region regardless of the Watson-Crick or wobble nature of the base pairing. However, none of the five known picornavirus IRES structures (types I-V) or the known conserved 5'UTR-IRES nt motifs [5] could be identified in the new sequence.

The predicted length of the coding region (ORF) is 6,990 nt, and it encodes a single 2,329-aa-long polyprotein (Fig. 1). The predicted capsid proteins (VP0, VP3, and VP1) had the highest aa sequence identity of $51.79 \%$ (coverage: $99 \%$ ),
P4/P4' cleavage sites are indicated above the genome map. Question marks and dotted lines indicate the uncertain borders of VP3/VP1, $\mathrm{VP} 1 / 2 \mathrm{~A}_{1}$, and $2 \mathrm{C} / 3 \mathrm{~A}$. The IRES type of the 5'UTR is unknown (see Fig. 2). aa, amino acid; nt, nucleotide; RdRp, RNA-dependent RNA polymerase; UTR, untranslated region; VP, viral protein

$43.05 \%$ (coverage: $92 \%$ ), and $38.79 \%$ (coverage: $88 \%$ ) to the corresponding proteins of Wenling lepidotrigla picornavirus (MG600079), eel picornavirus strain F15/05 (NC_022332), and Wenling lepidotrigla picornavirus (MG600079), respectively, using GenBank BLASTp. The complete capsid polyprotein (P1) shows the highest sequence identity (41.4\%; coverage: $96 \%$ ) to the corresponding polyprotein of Wenling lepidotrigla picornavirus (MG600079). In the non-structural region, two potential $2 \mathrm{~A}$ proteins were predicted: the 19-aalong $2 \mathrm{~A}_{1}{ }^{\mathrm{NPG} \downarrow \mathrm{P}}$ and the 137 -aa-long $2 \mathrm{~A}_{2}{ }^{\mathrm{H}-\mathrm{box} / \mathrm{NC}}$ (Fig. 1). The $2 \mathrm{C}$ possesses the GxxGxGKS $\left(\mathrm{G}_{1174}\right.$ PAGCGKS) motif for nucleotide triphosphate binding and the $\mathrm{D}_{1237}$ DMGQ motif for putative helicase activity [11]. The $2 \mathrm{C}$ protein shows the highest aa sequence identity ( $38.1 \%$, coverage: $94 \%)$ to the corresponding protein of eel picornavirus (NC_022332). The picornavirus $3 \mathrm{C}$ protease catalytic triad and well-conserved aa motifs of 3D (RNA-dependent RNA polymerase) are present in the study strain (Fig. 1) [3, 10]. The 3CD proteins show the highest aa sequence identity $(47.3 \%$, coverage: $99 \%$ ) to the 3CD proteins of Wenling pleuronectiformes picornavirus (MG600098) from flatfish [20].

The 3'UTR is $148 \mathrm{nt}$ long. Partial nucleotide sequence similarity (84-91\% identity) was found between nt position 7,612 and 7,679 of the 3'UTR of European perch picornavirus to the 3'UTR regions of five picornaviruses, including Wenling lepidotrigla picornavirus (MG600079), Yancheng osbecks grenadier anchovy picornavirus (MG600099), potamipivirus A (MK189163), eel picornavirus (KC843627), and Wenling hoplichthys picornavirus (MG600101), using GenBank BLASTn search (Fig. 2). All 


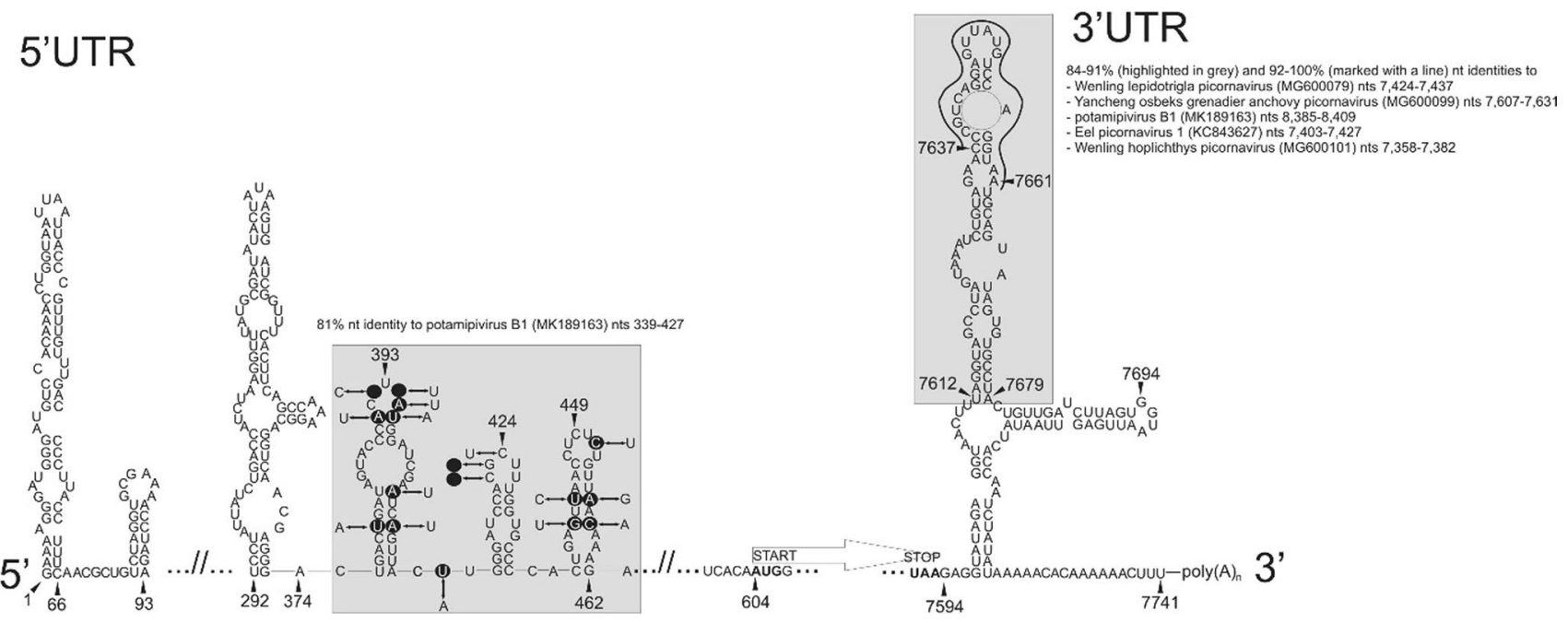

Fig. 2 Predicted RNA secondary structure of the 5'UTR (left side; partial) and 3'UTR (right side; complete) of the genome sequence of perchPV/M9/2015/HUN. Significant nucleotide sequence similarity to other fish-origin picornaviruses, identified using BLASTn, are highlighted with a grey background. In the 5'UTR, the majority of the nucleotide mutations maintained their base pairing (and therefore the predicted secondary RNA structures) when perchPV/M9/2015/
HUN and potamipivirus B1 (MK189163) were compared. In the 3'UTR, the stem-loop structure at the apex (indicated by a line) is highly conserved (92-100\% identity) in perchPV/M9/2015/HUN and five other fish-origin picornavirus nucleotide sequences. The protein coding region extends from nucleotides 604 to 7593 in perchPV/ M9/2015/HUN in a single open reading frame (ORF). of these picornaviruses were identified in different fish species. Especially high (92-100\%) nt sequence identity was found within the region between nt position 7,637 and 7,661 of the 3'UTR of European perch picornavirus (Fig. 2). We used these six 3'UTR nt sequences to predict the RNA secondary structure of the 3'UTR (Fig. 2). We found that the majority of the nucleotide mutations maintained their base pairing (data not shown), and therefore, the predicted RNA secondary structure, especially that of the stem-loop at the apex is highly conserved in all of the sequences (Fig. 2). The 3'UTR has 64.2\% A+U content.

Phylogenetic analysis (Fig. 3) based on the amino acid sequences of the $\mathrm{P} 1,2 \mathrm{C}$, and $3 \mathrm{CD}$ proteins showed that perchPV/M9/2015/HUN represents a distinct lineage among picornaviruses, but it is clustered together with the main group of known but presently unassigned fish picornaviruses.

The prevalence of the novel picornavirus genome was tested by RT-PCR in faecal samples from a total of 13 different freshwater fish species (Supplementary Table S1). A total of eight (12.9\%) of the 62 faecal samples from three fish species were positive by RT-PCR for the study strain: three $(37.5 \%)$ of eight, two (28.6\%) of seven, and three (75\%) of four specimens from European perch, zander, and black bullhead, respectively (Supplementary Table S1). Sequence analysis revealed that all of the sequences of 257-bp-long PCR products obtained using the PerchPVscreen2-F/R primers were $100 \%$ identical to each other.

\section{Discussion}

Since the first confirmed report in 2014 [4], accumulating data have shown that fish are important vertebrate hosts of picornaviruses and therefore should not be neglected in picornaviral studies. Theoretically, and from an evolutionary point of view, lower vertebrates have been infected with a larger number of viruses and with genetically more diverse viruses than mammals. At present, six official fishorigin genera of picornaviruses (Limnipivirus, Potamipivirus, Fipivirus, Symapivirus, Rajidapivirus, and Danipivirus) have been established, but several picornaviruses identified in saltwater and freshwater fishes are waiting for their official taxonomy to be determined [20]. This study reports the complete genome characterization and molecular epidemiology of an additional novel picornavirus from freshwater fish. According to the current ICTV Picornaviridae Study Group taxonomy guidelines (http:// www.picornastudygroup.com/definitions/genus_definition. $\mathrm{htm}$ ), one of the criteria for creating a new picornavirus genus is significant divergence of the orthologous protein sequences: exceeding $66 \%$ for $\mathrm{P} 1$ and $64 \%$ for $2 \mathrm{C}, 3 \mathrm{C}$, and 3D. Based on complete genome sequencing and comparative analysis, the strain reported here may represent a novel species and form a potential novel picornavirus genus in a populated monophyletic group of picornaviruses identified in fish. 


\section{(a) P1}

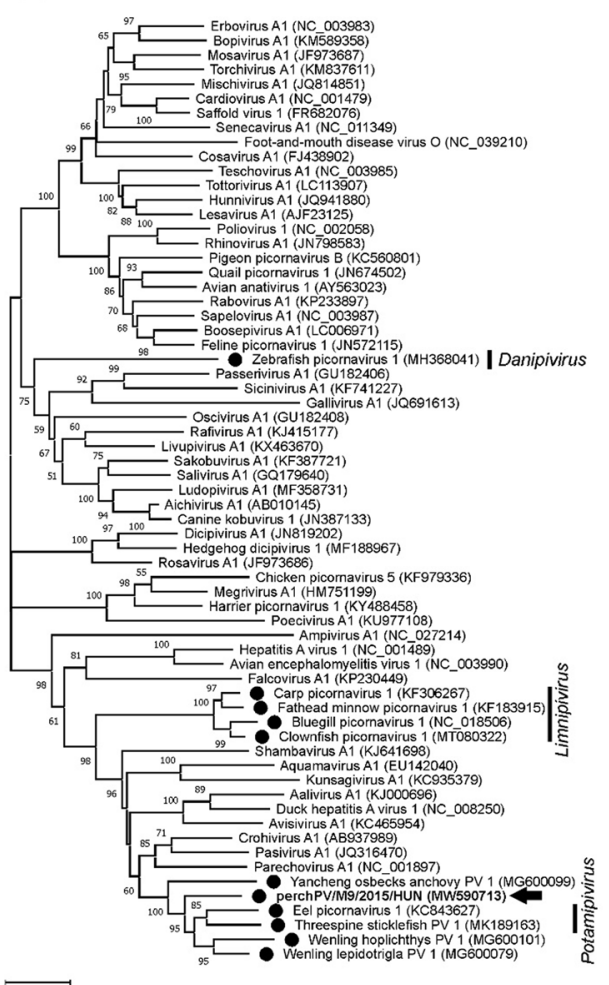

(b) $2 \mathrm{C}$

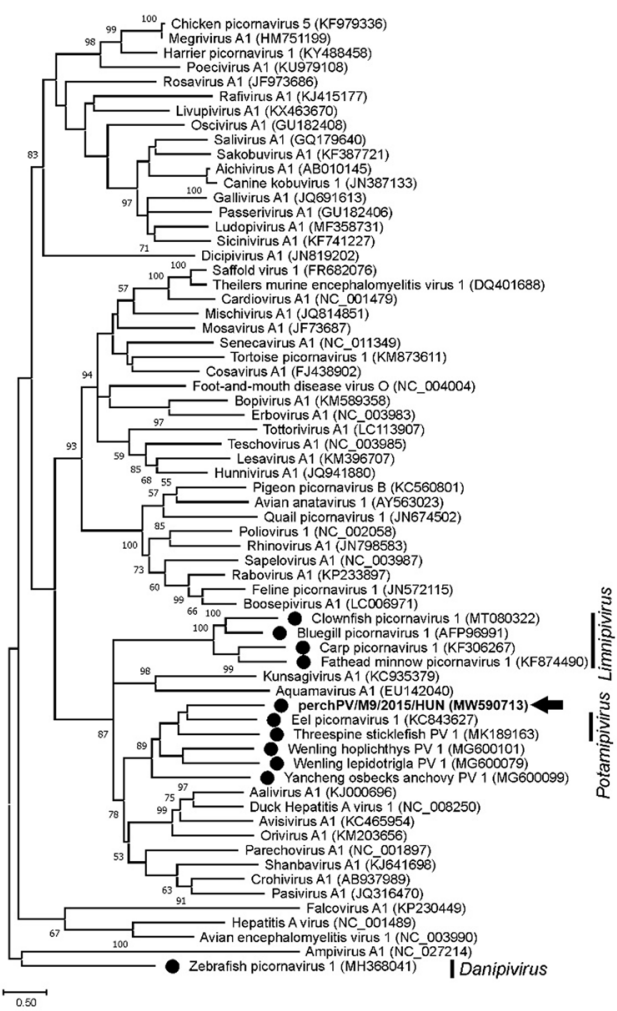

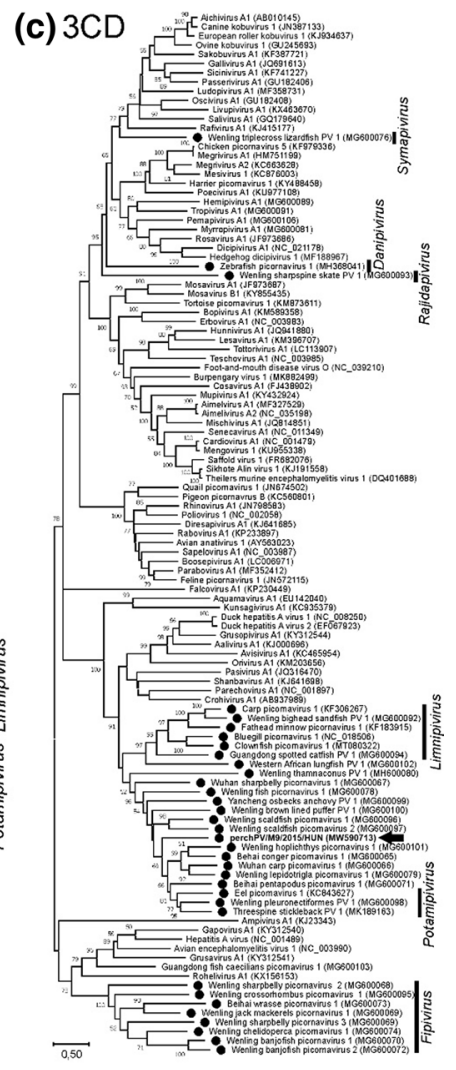

Fig. 3 Phylogenetic analysis of the (a) P1, (b) 2C, and (c) 3CD proteins of prototype picornaviruses representing picornavirus genera and fish-origin picornaviruses, including the study strain perchPV/ M9/2015/HUN (MW590713, bold letter and black arrows). Fishorigin picornaviruses are indicated by black dots. The names of the officially accepted picornavirus genera of fish origin are indicated. The 3CD tree includes all of the available fish-origin picornavirus

Partial but significant nucleotide sequence similarity was identified in the 5' and 3' UTRs of perchPV/M9/2015/ HUN and five other fish-origin picornaviruses. The RNA secondary structure of these UTRs is not known, but they could have a common origin. Based on their sequence similarity and presumed structural analogy, the partial 5'UTR and the complete 3'UTR secondary RNA structure could be predicted. While the detailed 5'UTR structure, especially the type of the internal ribosome entry site (IRES) remains unknown, the stem-loop structure in the apical part of the 3'UTR is highly conserved in these virus sequences.

PerchPV/M9/2015/HUN was identified in faecal specimens from different fish living in geographically separated open-air fish pond habitats. Whether this virus infects and replicates in specific tissues in different fish species or is able to cause symptomatic infections remains to be determined.

Investigation of the virome, including picornaviruses, of lower vertebrates contributes to our understanding of viral evolutionary relationships and allows the identification of possible disease-causing picornaviruses associated
$3 \mathrm{CD}$ protein sequences in the GenBank database. The $\mathrm{P} 1$ and $2 \mathrm{C}$ trees show only selected fish-origin picornavirus $\mathrm{P} 1$ and $2 \mathrm{C}$ protein sequences, mainly those most closely related to the study strain. Phylogenetic trees were constructed in MEGA X, using the maximumlikelihood method with the $\mathrm{LG}+\mathrm{F}+\mathrm{G}+\mathrm{I}$ model for the P1 and $3 \mathrm{CD}$ regions and the $\mathrm{LG}+\mathrm{I}+\mathrm{G}$ model for the $2 \mathrm{C}$ region. Bootstrap values (based on 1000 replicates) for each node are given if $>50 \%$.

with wild, experimental, and farmed fish bred for human consumption.

Supplementary Information The online version contains supplementary material available at https://doi.org/10.1007/s00705-021-05167-y.

Acknowledgements This work was supported by a grant from the Hungarian Scientific Research Fund (OTKA/NKFIH K111615 and NKFIH FK134311) and the PTE-ÁOK-KA No. 2020/14 of the Medical School, University of Pécs. P.P. was supported by the János Bolyai Research Scholarship of the Hungarian Academy of Sciences. P.P. and B.Á. were supported by the György Romhányi Research Scholarship of the University of Pécs, Medical School.

Funding Open access funding provided by University of Pécs. Hungarian Scientific Research Fund (OTKA/NKFIH K111615 and FK134311), Hungarian Nature Research Society and PTE ÁOK-KA (No: 2020/14).

\section{Declarations}

Conflict of interest The authors declare that they have no conflict of interest. 
Open Access This article is licensed under a Creative Commons Attribution 4.0 International License, which permits use, sharing, adaptation, distribution and reproduction in any medium or format, as long as you give appropriate credit to the original author(s) and the source, provide a link to the Creative Commons licence, and indicate if changes were made. The images or other third party material in this article are included in the article's Creative Commons licence, unless indicated otherwise in a credit line to the material. If material is not included in the article's Creative Commons licence and your intended use is not permitted by statutory regulation or exceeds the permitted use, you will need to obtain permission directly from the copyright holder. To view a copy of this licence, visit http://creativecommons.org/licenses/by/4.0/.

\section{References}

1. Altan E, Kubiski SV, Boros Á, Reuter G, Sadeghi M, Deng X, Creighton EK, Crim MJ, Delwart E (2019) A Highly divergent picornavirus infecting the gut epithelia of zebrafish (Danio rerio) in research institutions worldwide. Zebrafish 16(3):291-299

2. Altschul SF, Madden TL, Schäffer AA, Zhang J, Zhang Z, Miller W, Lipman DJ (1997) Gapped BLAST and PSI-BLAST: a new generation of protein database search programs. Nucleic Acids Res 25:3389-3402

3. Argos P, Kamer G, Nicklin MJ, Wimmer E (1984) Similarity in gene organization and homology between proteins of animal picornaviruses and a plant comovirus suggest common ancestry of these virus families. Nucleic Acids Res 12(18):7251-7267

4. Barbknecht M, Sepsenwol S, Leis E, Tuttle-Lau M, Gaikowski M, Knowles NJ, Lasee B, Hoffman MA (2014) Characterization of a new picornavirus isolated from the freshwater fish Lepomis macrochirus. J Gen Virol 95(3):601-613

5. Belsham GJ (2009) Divergent picornavirus IRES elements. Virus Res 139(2):183-192

6. Benson DA, Cavanaugh M, Clark K, Karsch-Mizrachi I, Lipman DJ, Ostell J, Sayers EW (2013) GenBank. Nucleic Acids Res 41:D36-42

7. Deng X, Naccache SN, Ng T, Federman S, Li L, Chiu CY, Delwart E (2015) An ensemble strategy that significantly improves de novo assembly of microbial genomes from metagenomic nextgeneration sequencing data. Nucleic Acids Res 43:e46

8. Farkas SL, Ihász K, Fehér E, Bartha D, Jakab F, Gál J, Bányai K, Marschang RE (2015) Sequencing and phylogenetic analysis identifies candidate members of a new picornavirus genus in terrestrial tortoise species. Arch Virol 160:811-816

9. Fichtner D, Philipps A, Groth M, Schmidt-Posthaus H, Granzow H, Dauber M, Platzer M, Bergmann SM, Schrudde D, Sauerbrei A, Zell R (2013) Characterization of a novel picornavirus isolate from a diseased European eel (Anguilla anguilla). J Virol 87(19):10895-10899

10. Gorbalenya AE, Donchenko AP, Blinov VM, Koonin EV (1989) Cysteine proteases of positive strand RNA viruses and chymotrypsin-like serine proteases: a distinct protein superfamily with a common structural fold. FEBS Lett 243(2):103-114

11. Gorbalenya AE, Koonin EV, Wolf YI (1990) A new superfamily of putative NTP-binding domains encoded by genomes of small DNA and RNA viruses. FEBS Lett 262(1):145-148

12. Hahn MA, Dheilly NM (2019) Genome characterization, prevalence and transmission mode of a novel picornavirus associated with the threespine stickleback fish (Gasterosteus aculeatus). J Virol 93:e02277-e2318

13. Lange J, Groth M, Fichtner D, Granzow H, Keller B, Walther M, Platzer M, Sauerbrei A, Zell R (2014) Virus isolate from carp: genetic characterisation reveals a novel picornavirus with two aphthovirus 2A-like sequences. J Gen Virol 95:80-90

14. Mor SK, Phelps NBD (2016) Picornaviruses of fish. In: Kibenge FSB, Godoy MG (eds) Chapter 21, Agriculture virology. Academic Press, pp 337-348

15. Ng TF, Wellehan JF, Coleman JK, Kondov NO, Deng X, Waltzek TB, Reuter G, Knowles NJ, Delwart E (2015) A tortoise-infecting picornavirus expands the host range of the family Picornaviridae. Arch Virol 160(5):1319-1323

16. Pankovics P, Boros Á, Tóth Z, Phan TG, Delwart E, Reuter G (2017) Genetic characterization of a second novel picornavirus from an amphibian host, smooth newt (Lissotriton vulgaris). Arch Virol 162:1043-1050

17. Phan TG, Vo NP, Boros Á, Pankovics P, Reuter G, Li OT, Wang C, Deng X, Poon LL, Delwart E (2013) The viruses of wild pigeon droppings. PLoS ONE 8(9):e72787

18. Phelps NBD, Mor SK, Armien AG, Batts W, Goodwin AE, Hopper L, McCann R, Ng TFF, Puzach C, Waltzek TB, Delwart E, Winton J, Goyal SM (2014) Isolation and molecular characterization of a novel picornavirus from baitfish in the USA. PLoS ONE 9(2):e87593

19. Reuter G, Boros Á, Tóth Z, Phan TG, Delwart E, Pankovics P (2015) A highly divergent picornavirus in the amphibian the smooth newt (Lissotriton vulgaris). J Gen Virol 96:2607-2613

20. Shi M, Lin XD, Chen X, Tian JH, Chen LJ, Li K, Wang W, Eden JS, Shen JJ, Liu L, Holmes EC, Zhang YZ (2018) The evolutionary history of vertebrate RNA viruses. Nature 556:197-202

21. Victoria JG, Kapoor A, Li L, Blinkova O, Slikas B, Wang C, Naeem A, Zaidi S, Delwart E (2009) Metagenomic analysis of viruses in stool samples from children with acute flaccid paralysis. J Virol 83:4642-4651

22. Zuker M (2003) Mfold web server for nucleic acid folding and hybridization prediction. Nucleic Acids Res 31(13):3406-3415

Publisher's Note Springer Nature remains neutral with regard to jurisdictional claims in published maps and institutional affiliations. 